\title{
O modelo de codificação e decodificação de Stuart Hall e as atuais \\ Interfaces Naturais de Usuário
}

\section{The Stuart Hall encoding and decoding model and the current Natural User Interfaces}

\author{
Guilherme Philippe Garcia Ferreira \\ Doutor em Design pela Universidade Federal do Paraná (UFPR) - prof.guilhermepgf@gmail.com
}

Adriano Heemann

Doutor em Engenharia Mecânica pela Universidade Federal do Paraná (UFPR). Professor da Universidade Federal do Paraná (UFPR) - adriano.heemann@gmail.com

\section{Resumo}

A cada novo ciclo de desenvolvimento tecnológico surgem interfaces e interações que solicitam um novo olhar sobre a informação. Neste ensaio, discutimos a Interação Humano-Computador por meio do diálogo entre a produção Codificação $e$ Decodificação, de Stuart Hall, com as Interfaces Naturais de Usuário, em especial no contexto ainda pouco explorado da háptica. Com este estudo, sugerimos que a codificação de elementos táteis não deve ser considerada mera aplicação de uma representação real no ambiente simulado. Ela pode ser tratada, sobretudo, como um modo de compreensão dos referenciais e conhecimento dos envolvidos. Para tanto, iniciamos uma contextualização das características apontadas no referido trabalho de Hall, traçamos paralelos com as Interfaces Naturais de Usuário, os referenciais táteis, a construção da imagem e, por fim, o projeto destas informações nos ambientes interativos. Não é nossa pretensão exaurir todas as possibilidades do diálogo, mas caracterizar pontos gerais do discurso dos documentos apresentados, explorar suas convergências e lacunas. Com esta contribuição ao campo teórico pretendemos que o leitor ambicione explorar ainda mais as relações possíveis entre os estudos da comunicação e os novos canais informacionais. Palavras-chave: Design de interação. Interface háptica. Comunicação.

\begin{abstract}
The ethnographic approach has been increasingly adopted at different stages of design process. At the beginning of the project, it can assume a strategic role and assist in identifying the users' needs. However, Anthropology (area of ethnography origin) and Design differ in terms of purpose, time spent for research and knowledge acquired during a training of professionals and, after that, it is understood that the ethnographic approach must passes through adaptations to be applied in the area of Design. With this study, we sought to understand how an ethnographic approach presents itself when it is applied at the beginning of the design process to identify the users' needs. Therefore, they were investigated the occurrence of ethnographic research as a scientific method and the field research with users in process design. As result, were defined the main aspects of ethnographic approach applied to design and identified some users' research methods influenced by such aspects. It was realized that the ethnographic approach has been used in companies through the application of methods that presents the aspects identified in this study. These methods are based, mainly, on observation in context and conversation, in which it is sought to understand deeply how users behave in reality and thus, identifying their needs and projects to meet them.
\end{abstract}

Keywords: Interaction design. Haptic interface. Communication.

Recebido em: 22/11/2017

Aceito em: 19/07/2018 


\section{INTRODUÇÃO}

O documento central que tece as informações deste ensaio foi produzido por Stuart Hall em 1973, com o título Codificação e Decodificação no Discurso Televisivo e representa uma das principais obras do autor, que aqui será chamado apenas como Codificação e Decodificação. 0 texto disponível em (HALL, 2006, p. 359) conta também com uma entrevista do teórico e continua alvo de pesquisa e debate no meio acadêmico, apesar do próprio Hall afirmar que nunca pretendeu trazer um modelo determinista para a temática:

\footnotetext{
O modelo de codificação/ decodificação não era um grande modelo. Eu tinha o Centre for Mass Communications Research na mira - eram eles que eu estava tentando afundar. Não pensava que o artigo geraria um modelo que duraria pelos próximos 25 anos. Não penso que ele tem o rigor teórico, a lógica interna e a consistência conceitual para isso.
}

Stuart Hall expôs esta opinião ao ser entrevistado em fevereiro de 1989 na Universidade de Massachusetts. O objetivo da entrevista era lançar um novo olhar sobre o artigo Codificação e Decodificação. O mesmo objetivo é perseguido no presente ensaio. Para tornar nossa motivação ainda mais clara, indagamos sobre a possível relevância do discurso de Hall para o atual contexto de interações considerando as Interfaces Naturais de Usuário (NUI - Natural User Interfaces). Ao modelo de Codificação e Decodificação aproximamos o conteúdo do livro intitulado Brave NUI World de Wigdor, Wixon (2011). Esse título faz uma homenagem evidente ao conto de Aldous Huxley de 1932, o Admirável Mundo Novo (Brave New World), que nos auxiliará neste primeiro momento a uma compreensão inicial do modelo de Codificação e Decodificação de Hall.

Desta forma, considerando o contexto da obra de (HUXLEY, 2009), faremos uma primeira exploração do discurso antes de avançarmos para as Interfaces Naturais de Usuário. Observemos desde já o título traduzido para o português e pelo qual o termo "brave" passou a ser "admirável". Nesta tradução, tem-se um dos pontos do discurso de Hall (2006; p. 390) explicitado:

Antes que essa mensagem possa ter um "efeito", satisfaça uma "necessidade" ou tenha um "uso", deve primeiro ser apropriada como um discurso significativo e ser significativamente decodificada.

Percebe-se que entre a composição do título original e sua versão traduzida para o português ocorre uma perceptível diferença de significados. O termo original "brave" permite 
isoladamente traduções como bravo, valente, corajoso. Enquanto na composição "brave new" entendemos algo novo, mas que possivelmente não será bom ou bem-sucedido (CAMBRIDGE DICTIONARY, 2017). Por outro lado, a versão em português nos remete a uma inferência mais positiva, algo maravilhoso que causa encantamento ou surpresa. Ora, os significados não nos parecem ser os mesmos. Ainda que por uma ótica preliminar, já nos foi possível detectar que o processo de codificação e decodificação passou por influências, tais como do próprio tradutor ou corpo editorial, que podem ter mudado significativamente o valor percebido pelo leitor de Huxley.

Avançando em nosso estudo, Wigdor e Wixon (2011) discutem o contexto atual da informática considerando seu desenvolvimento desde os primeiros computadores digitais até o estágio atual da evolução das interfaces. Para os autores, os computadores transcendem as barreiras internacionais e modificam a forma como as pessoas trabalham e se comunicam umas com as outras. Ou seja, os computadores não são mais produtos dedicados a uma ou outra classe de trabalhadores e fazem parte do cotidiano de grande parte da população urbana. Ora, mas se uma tradução de título, como exemplificado, já pode gerar significados diferentes daqueles codificados inicialmente pelo emissor, os desdobramentos da codificação e decodificação para o design de interação pode ser ainda mais complexo, ainda mais considerando formas de interação e comunicação entre o sistema e usuário pouco usuais como a háptica.

Assim, nos parece que o desenvolvimento tecnológico demanda o repensar das interações com os dispositivos e das linguagens utilizadas em sua construção de informação, em especial na interação háptica. Como já apontava (HALL, 2006, p. 388) “o acontecimento deve se tornar uma 'narrativa' antes que possa se tornar um evento comunicativo". Para nós, emerge daí uma nova questão: como é possível desenvolver narrativas no design de interação considerando as atuais tecnologias táteis para uma comunicação efetiva entre codificador e decodificador?

\section{INTERFACES NATURAIS DE USUÁRIO}

Para Wigdor e Wixon (2011) as Interfaces Naturais de Usuário (NUI) atualmente ocupam uma posição similar a das interfaces gráficas no início da década de 1980, com a promessa de reduzir ainda mais as barreiras da computação. Celulares, tabletes e computadores, que suportam a interação com o toque e gestual, também aproximam o usuário do objeto ou contexto virtual, tornando a ação parte essencial da comunicação, das entradas e saídas. 
Entretanto, entendemos que é necessário ter cautela. Assim como destacado no título do livro de Huxley, estas interfaces suscitam campos para discussões até mesmo de sua terminologia. Por exemplo, interfaces naturais para os usuários, interfaces naturais dos usuários, interfaces naturais com os usuários, interfaces naturais de uso são algumas das traduções possíveis para o termo em inglês Natural User Interface, que carregam diferentes significados e representações:

\footnotetext{
O termo natural é muitas vezes entendido como uma mímica do "mundo real". Na nossa opinião, é uma filosofia de design e uma fonte de métricas que permite um processo iterativo para criar um produto [...]. Nós vemos o natural como se referindo à maneira como os usuários interagem e sentem sobre o produto, ou mais precisamente, o que eles fazem e como eles se sentem enquanto o estão usando (WIGDOR; WIXON, 2011, p. 9, tradução nossa).
}

Assim, o natural é aquilo percebido naturalmente pelo usuário, mesmo quando não relacionado a uma ação possível no mundo real. O natural em NUI se refere a operações ou códigos que são assimilados e replicados sem uma alta consciência do operador. Hall também discorre nesta direção ao sugerir que "não há discurso inteligível sem a operação de um código" (HALL, 2006, p. 393). Se assumirmos a ótica de Hall, podemos dizer que a interação entre operador e máquina ocorre a partir de um conjunto de códigos que devem ser úteis tanto para o usuário quanto para a interface que o recebe. Hall (2006, p. 393) prossegue:

\footnotetext{
Certos códigos podem, é claro, ser tão amplamente distribuídos em uma cultura ou comunidade de linguagem específica, e serem aprendidos tão cedo, que aparentam não terem sido construídos - o efeito de uma articulação entre o signo e o referente - mas serem dados naturalmente.
}

Por exemplo, as interações por toque em celulares e tabletes acontecem atualmente de uma forma "profundamente naturalizada". Para a maioria dos usuários desses dispositivos, mesmo demandando um período de adaptação ou de aprendizagem diante de um novo aparelho, os padrões de operação para entrada e saída de informações são frutos de reconhecimentos aparentemente "naturais". No discurso de Hall percebemos que o natural é considerado algo "sem costura" e faz parte do nosso conhecimento já assimilado, podendo ser resgatado em um processo fluído e "sem emendas". Por exemplo, ao discutir o signo visual "vaca", Hall (2006, p. 393) argumenta: 


\begin{abstract}
Isso nos leva a pensar que o signo visual para "vaca" realmente é (em vez de representa) o animal [...] ainda mais no signo linguístico "vaca" [...] ambos em graus diferentes, são arbitrários em relação ao conceito do animal que representam. A articulação de um signo arbitrário com o conceito de um referente é o produto não da natureza, mas de uma convenção, e o convencionalismo dos discursos requer a intervenção e o apoio dos códigos.
\end{abstract}

Tomemos como exemplo a famosa obra de René Magritte (COCHRAN, 2006), na qual um artefato (imagem 1) é exibido com a legenda "Ceci n'est pas une pipe". A leitura de que "isto não é um cachimbo" nos força a perceber aquilo como o que é e não como o que representa.

Imagem 1 - A traição da imagem.

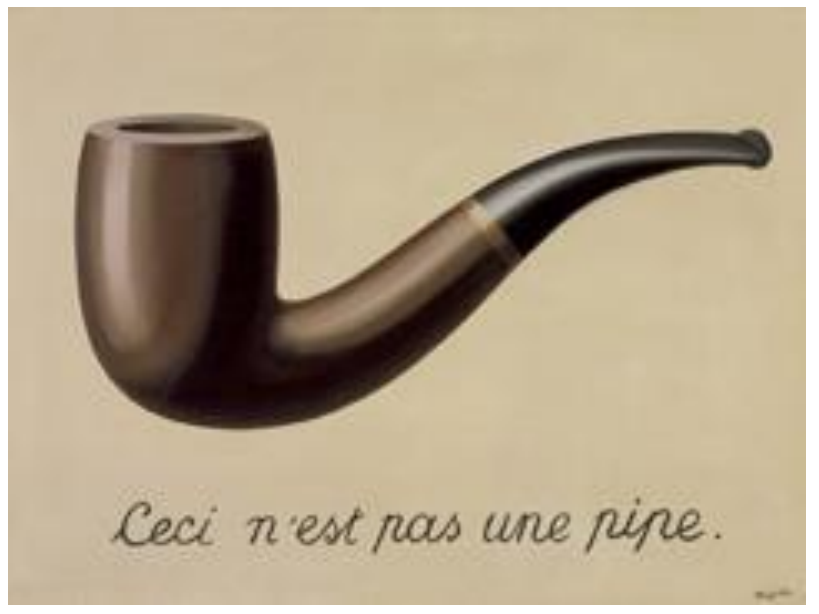

Fonte: Cochran (2006).

Atualmente esta obra de Magritte pode ser vista no Los Angeles County Museum of Art (LACMA). Para nós, ela também está conceitualmente amparada pelo discurso de Hall (2006). Da mesma forma que o autor discute que o signo "vaca" não é um representante imediato do animal e Magritte indica que sua obra não é um cachimbo, por sua vez, neste ensaio também não temos a pintura real do autor representada, mas uma reprodução que, desprovida de seu contexto original, pode trazer decodificações diversas do código do artista.

\title{
3 SIGNOS VISUAIS E TÁTEIS
}

No exemplo anterior, o signo visual do cachimbo parece ser dotado de algumas propriedades da "coisa representada" (HALL, 2006). Ou seja, embora saibamos que a imagem não é 
um cachimbo em seu estado real, tangível e tridimensional, percebemos tais características por meio do seu signo visual. Seguindo o mesmo princípio, em telas sensíveis ao toque de aparelhos eletrônicos, a constituição ou a configuração das ações que levam ao signo se tornam parte integrante da codificação do meio.

Podemos observar um exemplo disso no estudo de caso apresentado por Wigdor e Wixon (2011). O Palm Pilot (imagem 2) funciona como uma espécie de assistente pessoal digital lançado no mercado em 1997 pela empresa USRobotics.

Imagem 2 - PalmPilot e a linguagem Graffit.

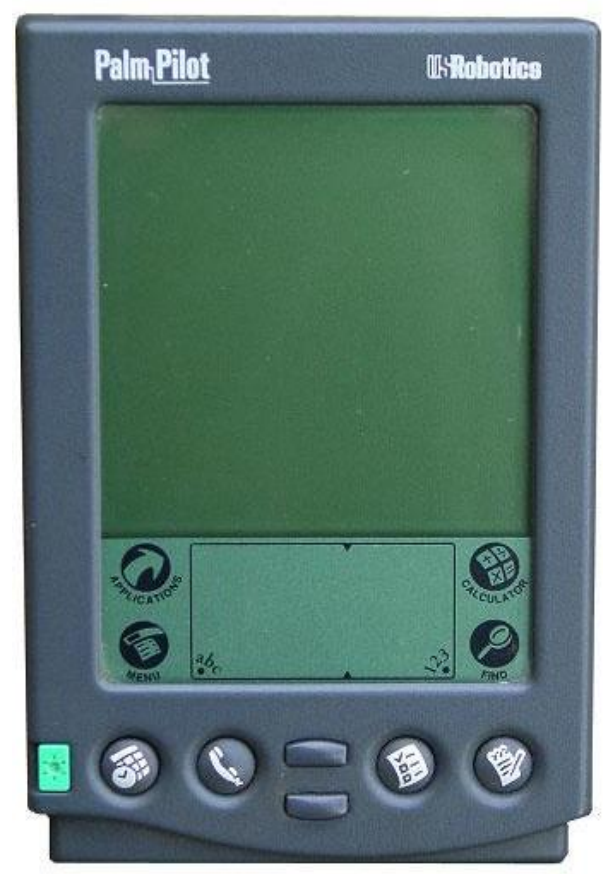

Graffiti Alphabet $(\bullet)$ Heavy dot indicates starting point.
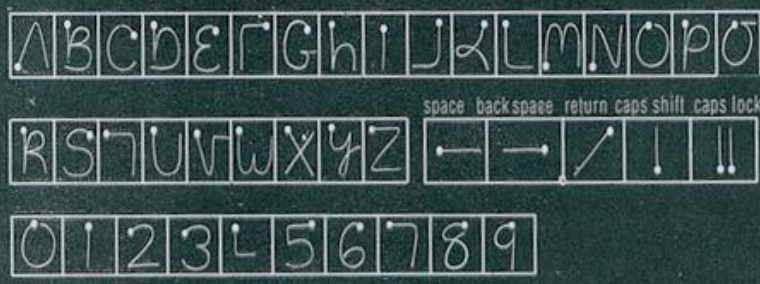

Punctuation Shift $=$ tap once $\quad$ (Write $\longrightarrow$ to exit a shift mode.)

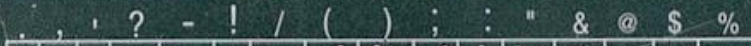

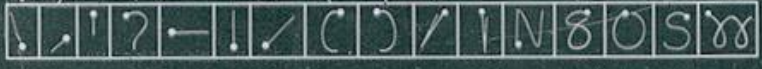

Fonte: PC Magazine (2011).

Os autores sugerem que os desenvolvedores do dispositivo Palm Pilot tomaram uma decisão fundamental ao planejar a Graffit. Wigdor e Wixon (2011) relatam que a baixa capacidade de processamento disponível na época e a restrição de memória do dispositivo tornaram o reconhecimento de caracteres desenhados arbitrariamente pelo usuário um grande desafio de processamento. A solução encontrada foi induzir o usuário a aprender a linguagem do aparelho, tecnologicamente mais leve de ser processada pelo software. Deste modo a entrada de dados era realizada seguindo o padrão do alfabeto Graffiti. 
Como apontam Wigdor e Wixon (2011), a linguagem Graffiti foi uma forma de entrada simplificada, mas que em virtude da sua proximidade com caracteres Romanos, permitiu uma curva de aprendizagem rápida. Após algum tempo de prática, a linguagem se tornava natural ao usuário.

Embora hoje em dia possa ser considerada como problemática do ponto de vista da usabilidade, na época a decisão pelo desenvolvimento desta linguagem nos parece ter garantido o sucesso comercial do produto. Trata-se de um bom exemplo de como uma necessidade tecnológica acabou produzindo uma interação que passou a ser considerada natural para seus usuários, a linguagem Graffiti.

O processo de geração desta linguagem se aproxima com a abordagem de Hall (2006, p. 389). Para ele, "é claro que processo de produção não é isento de seu aspecto "discursivo": ele também se constitui dentro de um referencial de sentidos e ideias". Ou seja, aquilo que o usuário conhece atua na formulação daquilo que ele compreende (imagem 3).

Imagem 3 - Diagrama Codificação e Decodificação.

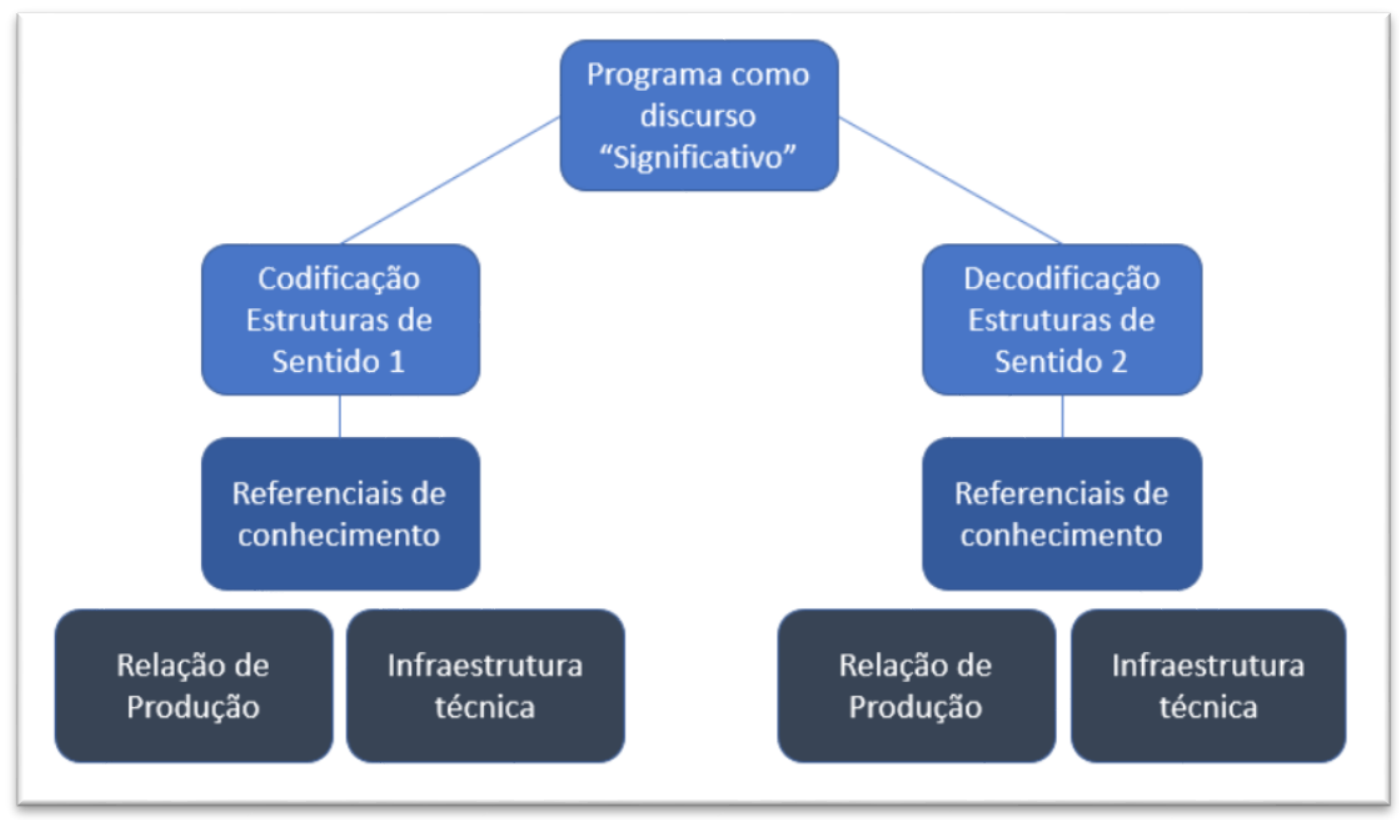

Fonte: Adaptado de Hall (2006).

Portanto, para o projeto destas NUI, é necessário compreender as capacidades do usuário e quais necessidades ou interesses a interface atende. Só assim é possível adequar as atividades atendendo às demandas do contexto Wigdor e Wixon (2011). 
Recorrendo ao diagrama de Codificação e Decodificação de Hall (imagem 3), assumimos como necessário conhecer profundamente o usuário, aquilo que constitui seu referencial de conhecimento e sentidos. Ou seja, é importante compreendê-lo como fonte e receptor da informação. Ao considerarmos a háptica como um dos objetos desse discurso, codificação e decodificação se alinham aos momentos de produção e percepção das sensações tangíveis. O usuário que usa o tato na aquisição da informação apresenta comportamento distinto daquele que só utiliza o visual:

O tato é um sentido que precisa ser realmente compreendido no ato de sua realização. Diferentemente da visão que é imediata, sintética, global, a percepção tátil é analítica. A polpa do dedo apreende parte por parte. Assim, o objeto explorado é conhecido da parte para o todo (ALMEIDA, 2017, p. 71).

Nesta mesma direção, a autora ainda reforça que é necessário adequar os objetos táteis às capacidades perceptivas, "objetos muito pequenos ou demasiadamente grandes são desaconselhados" (ALMEIDA, 2017, p. 72). Assim, para disponibilizar o recurso tátil em uma interface é preciso que o desenvolvedor responsável pela programação traduza a informação tátil planejada pelos projetistas - muitas vezes utilizando termos como áspero, liso, rugoso - por meio do conjunto de referenciais de seu conhecimento, ou seja, é fundamental a codificação desta informação no sistema.

Posteriormente, durante o uso do produto, esta informação é vinculada ao objeto significativo que é então decodificado ao ser percebido pelos dedos do usuário com base nos referenciais de seu conhecimento. Como observa Hall (2006, p. 391):

Os códigos de codificação e decodificação podem não ser perfeitamente simétricos. Os graus de simetria - ou seja, os graus de "compreensão" e "não-compreensão" na troca comunicativa - dependem dos graus de simetria/assimetria (relações de equivalência) estabelecidos entre as posições das "personificações" - codificador-produtor e decodificador-receptor.

Wigdor e Wixon (2011, p. 29, tradução nossa) corroboram com este discurso. Para os autores: 
O contexto profundo de interação é uma relação entre as duas ou mais partes em que a interface está agindo como facilitador não apenas para o resultado da transação, mas também para a relação entre os atores.

Esta relação nos parece ir ao encontro da crítica que Hall faz aos modelos de comunicação lineares - emissor, mensagem, receptor - uma vez que a mensagem também se articula e ganha novos significados através do próprio receptor. No campo da háptica, o código e sua decodificação dependem muitas vezes da capacidade associativa do perceptor como também de sua sensibilidade física ao meio tátil simulado.

Para a continuidade deste raciocínio recorremos à norma ISO 9241-910 (2011) que apresenta o conceito de háptica. De acordo com a norma, trata-se de um sentido viabilizado pelos receptores da pele, vinculados às relações do toque. No entanto, para Almeida (2017), estas relações perceptivas, de certo modo, parecem também depender do aprendizado, da aquisição de vivências e experiências com o toque. Só então é possível alguém compreender o significado de um estímulo háptico como sinônimo de informação.

Aqui nos apoiamos na seguinte afirmação de Hall (2006, p. 392):

O discurso visual traduz um mundo tridimensional em planos bidimensionais, ele não pode, é claro, ser o referente ou o conceito que significa. O cão no filme, pode latir, mas não consegue morder!

Em um filme suportado pela háptica, o cão até "poderia morder". Talvez, para o espectador, essa seria uma experiência de interação ingrata, mas tecnologicamente possível. Estudos recentes, como o apresentado por Munawar e Fischer (2016), descrevem o uso bemsucedido da tecnologia háptica para interações complexas, como cirurgias a distância, utilizando hardwares e softwares dedicados.

Em 2014, durante a Conferência Mundial Móvel sediada em Barcelona, na Espanha, a empresa Fujitsu apresentou um protótipo de tablete que simula as texturas que aparecem em sua tela. Essa tecnologia recebe o nome de "tecnologia sensorial tátil" e emprega vibrações ultrassônicas ou eletricidade estática para trazer sensações hápticas ao toque da tela, fazendo o usuário perceber pelo tato aquilo que também percebe pela visão (imagem 4). 
Durante a fase de codificação deste objeto, os programadores da Fujitsu tiveram que recorrer aos referenciais de conhecimento tátil e planejar as relações possíveis com o objeto em tela frente às possibilidades técnicas da infraestrutura disponível para, finalmente, criar um objeto visual-tátil significante. O usuário do tablete, por sua vez, provavelmente não tenha tido a oportunidade de passar sua mão em um crocodilo vivo, seja pelo risco que esta atividade representaria, seja pela crescente carência de crocodilos disponíveis nas cidades.

Imagem 4 - Protótipo háptico exibindo um crocodilo.

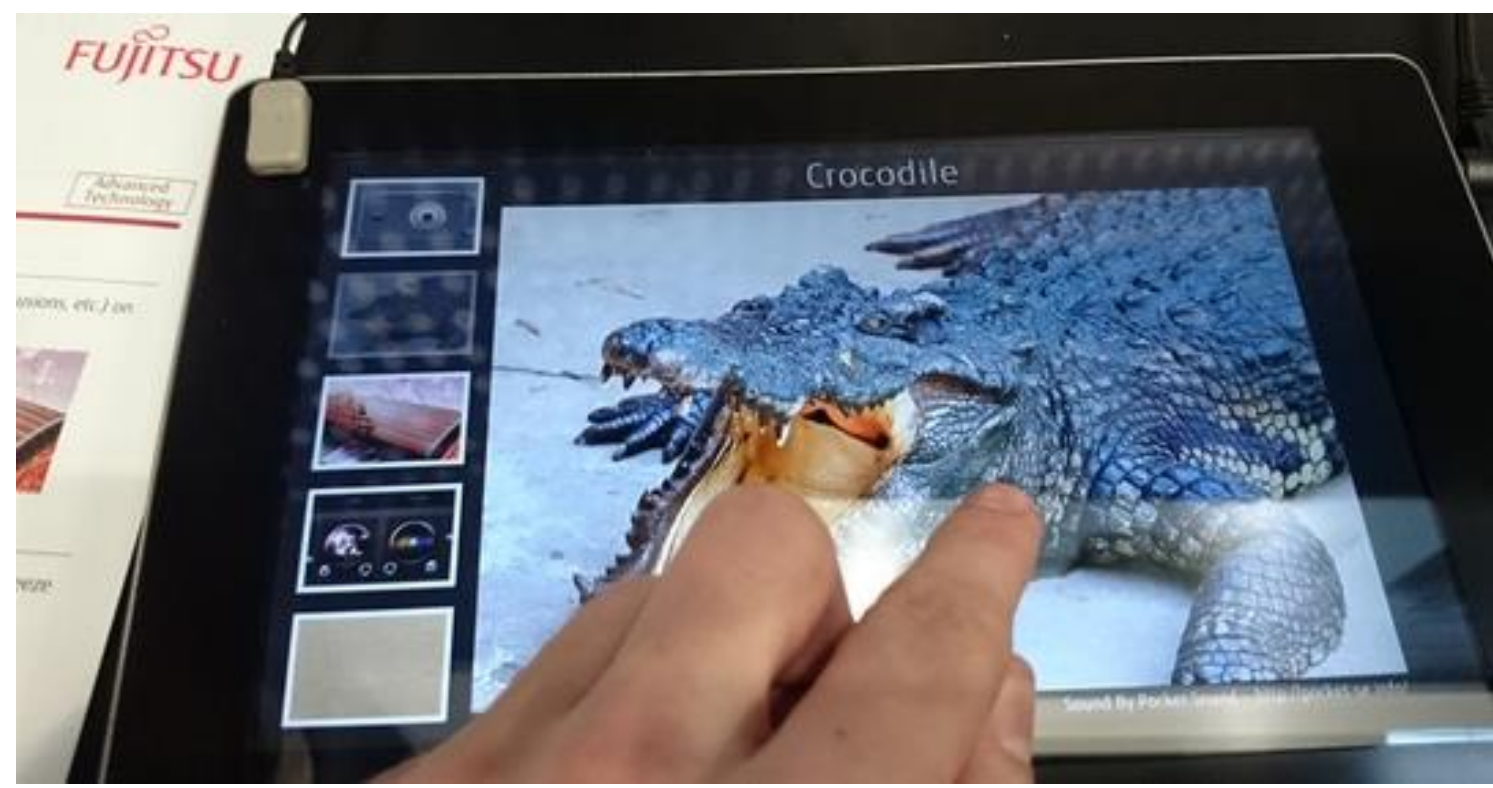

Fonte: Fujitsu Journal (2014).

Entendemos que o usuário do tablete consegue codificar o crocodilo apenas por meio dos seus sentidos auditivos e visuais. Mas é pela adição do sentido tátil correspondente que a experiência perceptiva se aprimora de modo importante. Bastos (2000, p. 2) aponta nesta direção:

O virtual revela uma outra experiência do real. As realidades virtuais não são irreais, pois possuem uma certa realidade que se desdobram em experiências virtuais com caráter sensorial "real" que são naturalmente acumuladas. As imagens virtuais não são simples ilusões visuais ou imagens de pura representação.

Assim, pela interação com o código tátil, a imagem mental da interação contemplará também a percepção sensorial como sendo real. Recorremos novamente ao trabalho de Almeida 
(2017) para exemplificar esta situação. A autora investiga principalmente a interação tátil considerando usuários cegos. Para este público, por mais que possa ser explicado oralmente o que é uma rosa, a construção imagética depende do entendimento sensorial do objeto.

\begin{abstract}
Para que uma pessoa cega tenha o conceito imagético da rosa é necessário tê-la ao alcance das mãos a fim de que possa efetivar-se uma análise pertinente através do toque; o tato apreende seu formato, seu tamanho, a configuração, a textura e a maciez de suas pétalas. $O$ olfato Ihe traz o aroma, o perfume que faz parte dela e completa o conceito a respeito da flor (ALMEIDA, 2017, p. 75).
\end{abstract}

É o conjunto de informações que forma a imagem tátil da rosa para o usuário. O referencial tátil anterior, neste caso, faz com que o usuário tenha maior facilidade de discriminar pontos que façam do objeto algo único, ao poder comparar o que está sentindo a outros dados recordados na memória. Parece que quanto menos desconexa do contexto naturalizado do usuário, mais perfeita se torna a experiência:

\begin{abstract}
Experiências perfeitas (sem emendas) permitem que os usuários estejam imersos para que adotem novas experiências. Você pode criar experiências perfeitas criando um ambiente que leve os usuários a suspender sua sensação de descrença, já não comparando suas ações com um padrão definido e experimentando uma conexão direta entre suas ações, os objetos e as operações do sistema (WIGDOR; WIXON, 2011, p. 43, tradução nossa).
\end{abstract}

Assim, durante a codificação, é necessário compreender os conhecimentos inerentes ao decodificador. Todavia, não se deve restringir a codificação a uma mera replicação do real. Consideramos interessante o repensar crítico a respeito do real frente ao contexto tátil proposto. Estamos aqui novamente nos baseando no discurso de Hall (2006, p. 399):

\footnotetext{
A menos que seja disparadamente aberrante, a codificação produz a formação de alguns dos limites e parâmetros dentro dos quais as decodificações vão operar [...]. Apesar disso, essa "correspondência" não é dada, mas construída. Não é "natural", mas produto de uma articulação entre dois momentos distintos.
}

A similaridade dos signos pode tornar o estranho mais próximo do referencial conhecido, mas nas interações táteis nem sempre este é o único caminho. Ao observar um usuário manipulando uma imagem em uma tela tátil percebemos que o usuário pode performar ações que são coerentes ao mundo real como, por exemplo, rotacionar a imagem movimentando os dedos na 
direção horária ou anti-horária. Entretanto, outras ações dependem de aceitar que, naquela linguagem gestual aplicada aos elementos representados em contexto bidimensional, existe uma interação que suplanta as capacidades do mundo real (WIGDOR; WIXON, 2011).

Por exemplo, aumentar uma foto ao afastar os dedos "segurando" as bordas da figura (imagem 5) é uma forma de interação própria deste meio e que, se for utilizada no mundo real não surtirá o mesmo efeito.

Imagem 5 - Manipulação de uma imagem.

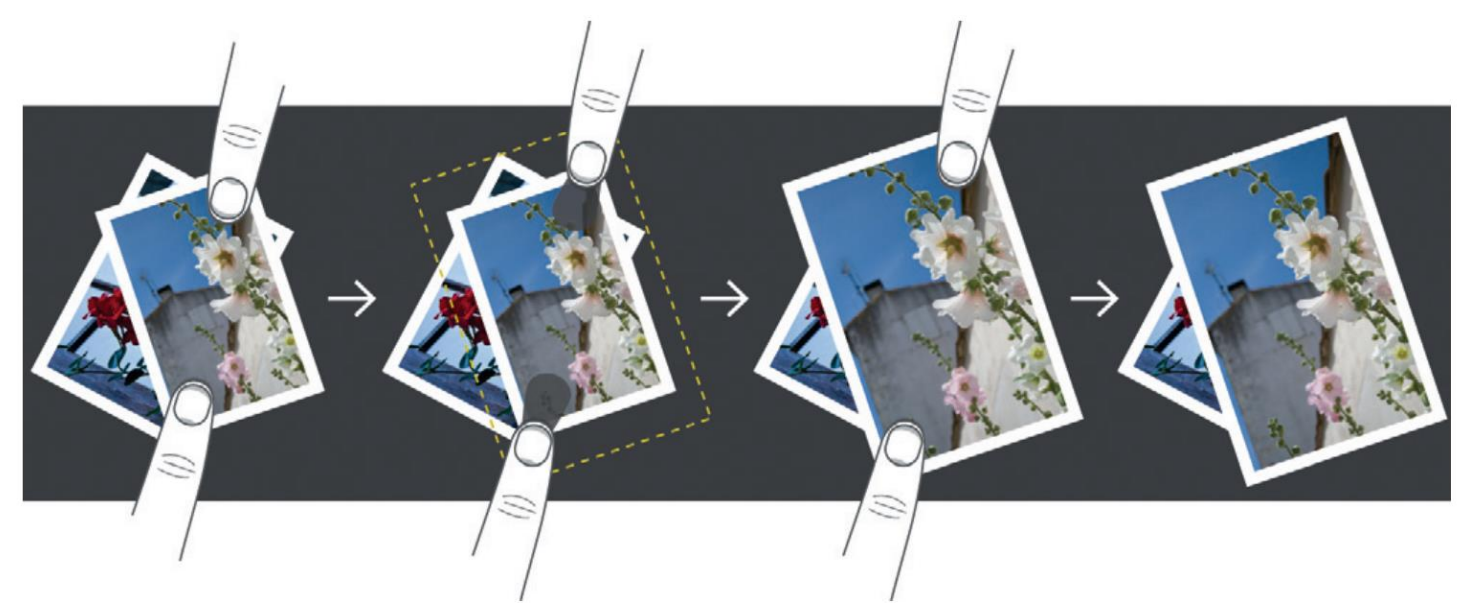

Fonte: Wigdor e Wixon (2011, p. 48).

No digital, o que podemos fazer e agir depende de aceitarmos a linguagem possível no contexto. Como aponta Hall (2006, p. 392):

A realidade existe fora da linguagem, mas é constantemente mediada pela linguagem ou através dela: e o que nós podemos saber e dizer tem de ser produzido no discurso e através dele.

As experiências perfeitas, sem emendas, são aquelas em que o usuário se encontra emocionalmente imerso, acolhendo as novas experiências que o ambiente possibilita e aprendendo a interagir cada vez mais com o meio (WIGDOR; WIXON, 2011). Para tanto, estas interações não podem ser completamente estranhas ao usuário. É necessário recorrer a conhecimentos prévios para reduzir a curva de aprendizagem. Este é um contexto complexo e garantir que a informação háptica seja percebida e compreendida de uma forma preferencial demanda testes e avaliações. Como aponta Hall (2006, p. 397): 


\begin{abstract}
O processo comunicativo não consiste na atribuição não-problemática de cada item visual a sua posição dentro de um conjunto de códigos pré-arranjados, mas sim em regras performativas, ou seja, regras de competência e uso, de logica aplicada - que buscam ativamente reforçar ou preferir um domínio semântico a outro e incluir e excluir itens dos conjuntos de sentido apropriados.
\end{abstract}

Como também observado no caso do Palm Pilot, se os usuários não tivessem "aceitado" o modelo preferido para inserção de dados através da linguagem Graffiti, possivelmente o produto não teria alcançado um público tão abrangente quanto o fez.

No contexto digital, parece que a velocidade em que ocorre a codificação e decodificação envolvendo o usuário depende da habilidade que este tem em reproduzir suas intenções e informações ao sistema. Assim como ocorre com uma pessoa que aprende um novo idioma ou desenvolve suas habilidades em um instrumento musical, nas interações com dispositivos móveis é igualmente importante que a experiência de interação seja uma extensão do usuário. Uma NUI adequada possibilita que os usuários se tornem especialistas na interação. De acordo com Wigdor e Wixon (2011, p. 44, tradução nossa):

\footnotetext{
Os especialistas agem como se houvesse uma conexão direta entre suas ações, todas as ferramentas que eles estão usando e o efeito resultante. Suas ações são fluidas e inteiras ao invés de estáticas e particularizadas.
}

Nesta direção, os autores recordam que NUI pode estar afastada de seu contexto e não produzir o efeito intencionado em sua codificação. Por exemplo, atualmente digitar um texto longo em uma interface de teclado virtual nos parece ser menos eficiente do que o mesmo trabalho em um teclado físico, onde posicionamento, distância entre teclas e referencial tátil são mais evidentes.

\title{
4 PROJETO DA INFORMAÇÃO
}

Os blocos que formam a linguagem de interação em um domínio são referidos por Wigdor e Wixon (2011) como "primitivos" ou, em uma tradução mais livre: "fundamentos". Para compreendermos estes fundamentos, devemos atentar a quatro níveis de ação: o que é fisicamente possível no dispositivo; o que é reconhecido e transmitido ao dispositivo; o que é reconhecido e gera respostas e como estas ações primitivas se transformam em controles 
específicos (WIGDOR; WIXON, 2011). Para compreendermos como a linguagem é codificada e decodificada, recorremos novamente ao discurso de Hall (2006) e listamos possíveis interações:

a) posição hegemônica-dominante: seria o caso de comunicação mais próxima do transparente. Neste sentido, durante uma interação, o usuário se apropria do sentido conotado "de forma direta e integral, e decodifica a mensagem nos termos do código referencial no qual ela foi codificada [...]". (HALL, 2006, p. 400)

b) posição código negociado: em uma NUI, o usuário poderia negociar a sua interação, reconhecendo os códigos legítimos, mas também adaptar e modificar as suas próprias regras. Esta versão negociada, segundo Hall (2006, p. 401):

contém uma mistura de elementos de adaptação e de oposição: reconhece a legitimidade das definições hegemônicas para produzir as grandes significações (abstratas), ao passo que, em um nível mais restrito, situacional (localizado), faz suas próprias regras - funciona com as exceções à regra.

c) posição código de oposição: o ambiente de NUI que se afasta em demasia de uma experiência perfeita, ou seja, distancia o usuário de um contexto imersivo e causa estranheza ou desconforto, pode fazer com que ele decodifique a informação com uma leitura contestatária. Não aceitando os significados, as interações, bem como a codificação e decodificação, o sistema perde sua validade.

Desta forma, a linguagem codificada deve se dotada de representações que se adéquem à percepção dos usuários. Falhas ou distanciamentos no processo de codificação podem acarretar em uma percepção inconsistente frente ao resultado pretendido pelo produtor. Como aponta Hall (2006, p. 398), "aquilo com que eles têm realmente de se confrontar é com a comunicação sistematicamente distorcida". Ou seja, é necessário que os produtores estejam mais preparados para codificar ao seu público, desconsiderando ou atualizando modelos de interação antigos.

Esse contexto com interações táteis, conforme Wigdor e Wixon (2011), demanda uma linguagem atualizada. Não basta uma simples tradução do que é aplicável a outros meios para as NUI. O objeto digital com referencial tátil ganha novas dimensões. Isso é o que Bastos (2000, p. 5) já havia percebido: 
As imagens mantêm o real a distância, pois é preciso ir além em busca de uma nova inteligibilidade, que visa a não passar apenas a imagem, mas a compreendê-la em sua essencialidade. A imagem precisa ser depurada, o que constitui o processo de "desimaginação".

Assim, ao explorar de forma tátil, a imagem é depurada e pode ser compreendida finalmente recorrendo às explorações anteriores que o usuário já vivenciou como também daquele que codificou a informação. Portanto, entendemos que é necessário considerar o contexto realmente aplicado, suas possibilidades, restrições e necessidades.

\section{CONSIDERAÇÕES FINAIS}

Neste ensaio, buscamos traçar um paralelo entre o discurso de Stuart Hall em Codificação e Decodificação e o ambiente ainda emergente das Interfaces Naturais de Usuários, principalmente ao tratar do referencial háptico. Iniciamos o texto com a abordagem das possíveis falhas na tradução da informação que podem culminar em compreensões distintas entre emissor e receptor.

Exploramos o referencial háptico como um campo de pesquisa incipiente e para o qual procuramos apresentar uma possível contribuição do modelo de Hall. Assim, destacamos aspectos da codificação e decodificação da informação, como o aspecto significativo do signo e referente e a estrutura de codificação e decodificação. Apoiados pelo trabalho de Wigdor e Wixon, contextualizamos conceitos básicos das NUI como a percepção natural das interações, a aproximação (mas não mímica) do real, e a experiência perfeita nas interações. Desta forma, sugerimos que as informações disponibilizadas em recursos digitais devem ser adequadas ao contexto no qual o usuário fim se insere, compreendendo e aplicando códigos que sejam significantes para seu referencial de conhecimento. Parece-nos que a háptica em dispositivos móveis é ainda um campo incipiente no qual as experimentações ainda são necessárias para compreender a validade das interações.

Por fim, apresentamos possíveis interações com base nas posições da informação que Hall discorre, tais como a posição hegemônica-dominante, negociada e de oposição, e a importância de um certo grau de simetria entre os códigos do codificador-produtor e decodificador-receptor. A compreensão das referências pré-existentes de quem codifica a informação, assim como as do receptor que irá decodificar estes dados, podem auxiliar no projeto de interações aparentemente naturais. Contudo não procuramos nos aprofundar em demasia nesta problemática, tampouco 
exaurir sua discussão. Pesquisas futuras poderiam investigar novos aspectos da comunicação e interação para compreender melhor as características deste contexto tecnológico emergente.

\section{AGRADECIMENTOS}

Os autores agradecem à CAPES e ao CNPq pelo apoio na forma de bolsa de estudos e bolsa de produtividade em pesquisa.

\section{REFERÊNCIAS}

ALMEIDA, Maria da Gloria de Sousa. Ver além do visível: a imagem fora dos olhos. 2017. $238 \mathrm{f}$. Tese Doutorado. Pontifícia Universidade Católica do Rio de Janeiro, Rio de Janeiro, 2017.

BASTOS, João Augusto de Souza Leão de Almeida. A imaterialidade da tecnologia. Educação \& Tecnologia, Curitiba, v. 5, n. 5. p. 11-29, 2000.

CAMBRIDGE DICTIONARY. Brave new. Base de dados. 2017. Disponível em: <https://dictionary.cambridge.org/pt/dicionario/ingles/brave-new>. Acesso em: 01 jan. 2017.

COCHRAN, Sara. Magritte and Contemporary Art: The Treachery of Images. Base de dados. 2006. Disponível em: <http://www.lacma.org/magritte-index>. Acesso em: 10 nov. 2017.

FUJITSU JOURNAL. Haptic interface of the future. Base de dados. 2014. Disponível em: <http://journal.jp.fujitsu.com/en/2014/04/15/01/>. Acesso em: 22 fev. 2017.

HALL, Stuart. Da diáspora: identidades e mediações culturais. Brasília: Editora UFMG, 2006.

HUXLEY, Aldous. Admirável mundo novo. Tradução Lino Vallandro; Vidal Serrano. São Paulo: Globo de Bolso, 2009.

ISO 9241-910. Ergonomics of human-system interaction-Part 910: framework for tactile and haptic interaction. ISO/TC 159 Ergonomics: ISO - International Organization for Standardization, 2011. Disponível em: <https://www.iso.org/standard/51097.html>. Acesso em: 22 fev. 2017.

MUNAWAR, Adnan; FISCHER, Gregory. Towards a haptic feedback framework for multi-DOF robotic laparoscopic surgery platforms. In: INTERNATIONAL CONFERENCE ON INTELLIGENT ROBOTS AND SYSTEMS, 2016, Daejeon. Browse Conferences..., Daejeon, IEEE, 2016. Diponível em: <https://ieeexplore.ieee.org/document/7759188>. Acesso em: 18 out. 2018.

PC MAGAZINE. R.I.P. palm: a history of the smartphone/PDA pioneer. Base de dados. 2011. Disponível em: <https://www.pcmag.com/feature/260439/r-i-p-palm-a-history-of-the-smartphonepda-pioneer>. Acesso em: 05 ago. 2017.

WIGDOR, Daniel; WIXON, Dennis. Brave NUI world: designing natural user interfaces for touch and gesture. San Francisco (USA): Morgan Kaufmann, 2011. 